\title{
Parameters that Affect the Color of Denture Resins
}

\author{
John M. Powers and Patrick J. Lepeak \\ School of Dentistry, The University of Michigan, Ann Arbor, Michigan 48109, USA
}

The effect of specular reflection, background color and specimen thickness on the color of four commercial denture resins was studied by reflection spectrophotometry. Higher values of luminous reflectance and excitation purity were obtained with a white than with a black background, whereas dominant wavelength was lowered slightly.

\section{J Dent Res 56(11):1331-1335 November 1977.}

The color of 24 commercial denture resins has been determined visually with Munsell color tabs and by reflection spectrophotometry. ${ }^{1}$ The best correlation between visual and spectrophotometric comparisons of the color of these resins was obtained when diffuse reflection of samples backed by a white standard was measured by the spectrophotometer. Clinically, the color of a denture base may be affected not only by the pigmentation of the resin but also by opacifiers in the resin, by the thickness and specular reflection of the denture, and by the color of the supporting tissues. The object of this research was to determine the effect of

Received for publication November 4, 1976.

Accepted for publication March 31, 1977.

This investigation was presented in part at the Ninth International Biomaterials Symposium in New Orleans, Louisiana, April 1977.

* COE-LOR Natural (Heavy), powder, Lot No. 090173, liquid, Lot No. 10058, Coe Laboratories, Inc., Chicago, Il 60658 .

† Permatone (Meharry), powder, Lot No. 10421204, liquid, Lot No. 10421267, Kerr Manufacturing Co., Romulus, Mi 48174.

$\$$ Hypro (Fibered Light), powder, Lot No. P73106, liquid, Lot No. L73179, L. D. Caulk Co., Milford, Del 19963.

\$ Perma-Cryl (Light), powder, Lot No. 090374, liquid, Lot No. 110174, Coe Laboratories, Inc., Chicago, II 60658 .

$I$ Bendick Polish, The Bendick Co., Lapeer, Mi.

\# ACTA C III UV-Visible Spectrophotometer, Beckman Instruments, Inc., Irvine, Ca 92664 .

** ASPH-U Integrating Sphere, Beckman Instruments, Inc., Irvine, Ca 92664.

\# Part No. 375287 , Beckman Instruments, Inc., Irvine, $\mathrm{Ca} 92664$.

$\dagger \dagger$ Part No. 104384, Beckman Instruments, Inc., Irvine, $\mathrm{Ca} 92664$.

种 International Commission on Illumination.

$\$ \S$ Munsell Color, Baltimore, Md 21218. specular reflection, background color and specimen thickness on the color of four commercial denture resins.

\section{Materials and Methods}

Blocks $(50 \times 50 \times \mathrm{T} \mathrm{mm})$ of four commercial denture resins coded $\mathrm{B} 5, * \mathrm{~B} 10, \dagger \mathrm{C} 6,+$ and $\mathrm{C} 11 \S$ were processed according to manufacturers' instructions and finished with fine pumice and then with a final polishing agent. Values of $\mathrm{T}$ were $1.30,2.50,5.61$, and 8.53 $\mathrm{mm}$, except for B5 and C11 for which specimens $8.53 \mathrm{~mm}$ thick were not made.

Curves of percent reflectance versus wavelength $(\lambda)$ were obtained for one sample of each resin between 405 and $700 \mathrm{~nm}$ with a double-beam, ultraviolet-visible spectrophotometer\# and integrating sphere. ${ }^{* *}$ Each resin was evaluated in the sample port (1 inch in diameter) under four conditions: (a) backed by a black standard\#-combined specular and diffuse reflectance, (b) backed by a black standard-diffuse reflectance only, (c) backed by a white standard ff-combined specular and diffuse reflectance, and (d) backed by a white standard-diffuse reflectance only. A second white standard was used in the reference port for calibration of zero and $100 \%$ reflectance and to obtain data. Tristimulus values $(\mathrm{X}, \mathrm{Y}, \mathrm{Z})$ relative to the 1931 CIEt+ color-matching functions for CIE standard illuminant $\mathrm{C}$ were determined by numerical integration $(\Delta \lambda=5$ $\mathrm{nm}$ ) as described elsewhere. ${ }^{2}$ Values of CIE chromaticity coordinates $(\mathrm{x}, \mathrm{y})$ were calculated from the tristimulus values ${ }^{2}$ and were used to obtain dominant wavelength (W) and excitation purity $(\mathrm{P})$ by a graphical technique with the use of a CIE chromaticity diagram (1931).§§ Luminous reflectance was equal to the tristimulus value, $Y$. An estimate of the opacity of each resin was obtained by calculation of the contrast ratio, ${ }^{3} Y_{b} / Y_{d}$, where the subscripts refer to the aforementioned experimental conditions. 

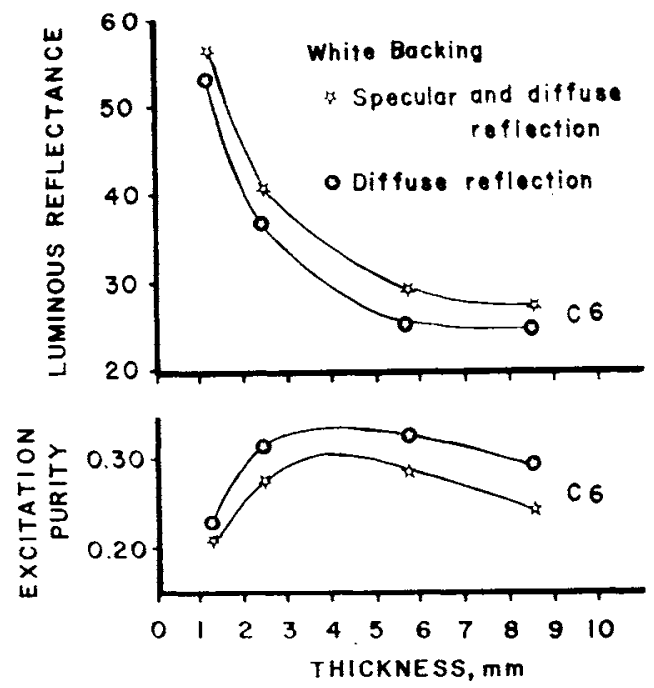

Fig 1.-Effect of specular reflection on luminous reflectance and excitation purity of C6.

The spectrophotometric parameters, luminous reflectance, dominant wavelength and excitation purity, were studied by a two-way analysis of variance 4 and means were compared with a Scheffe interval ${ }^{5}$ calculated at the $95 \%$ level of confidence. The error term of the analysis of variance for each parameter was estimated from the variance of nine replications of a resin determined under condition $\mathrm{d}$ in a previous study. ${ }^{1}$

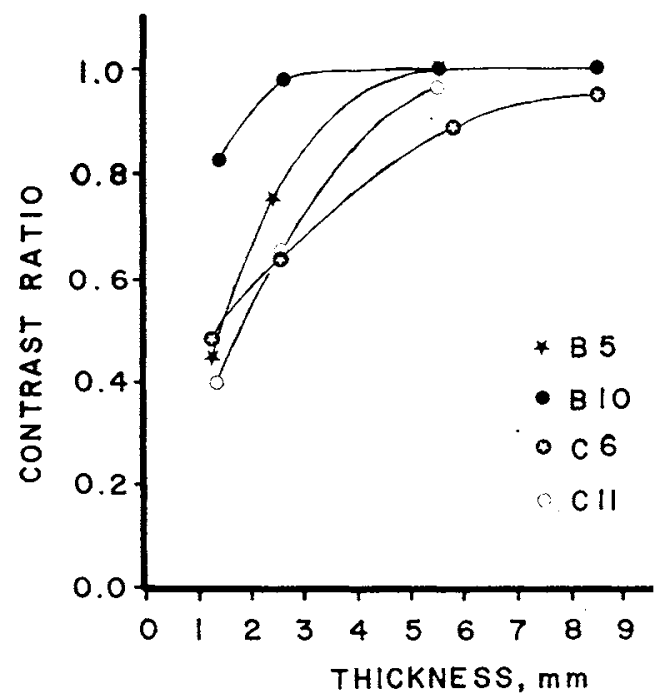

FIG 2.-Contrast ratio versus thickness for each resin.

\section{Results}

The effect of specular reflection on luminous reflectance and excitation purity is shown in Figure 1 for resin $\mathrm{C} 6$ as a function of thickness. Conditions $\mathrm{c}$ and $\mathrm{d}$ were significantly different from each other at each thickness for both luminous reflectance and excitation purity. The Scheffe intervals computed at the 95\% level of confidence were 0.16 and 0.005 , respectively. Values of luminous reflectance were increased, whereas values of excitation purity were decreased by specular reflection. Dominant wavelength was not affected significantly by specular reflection.

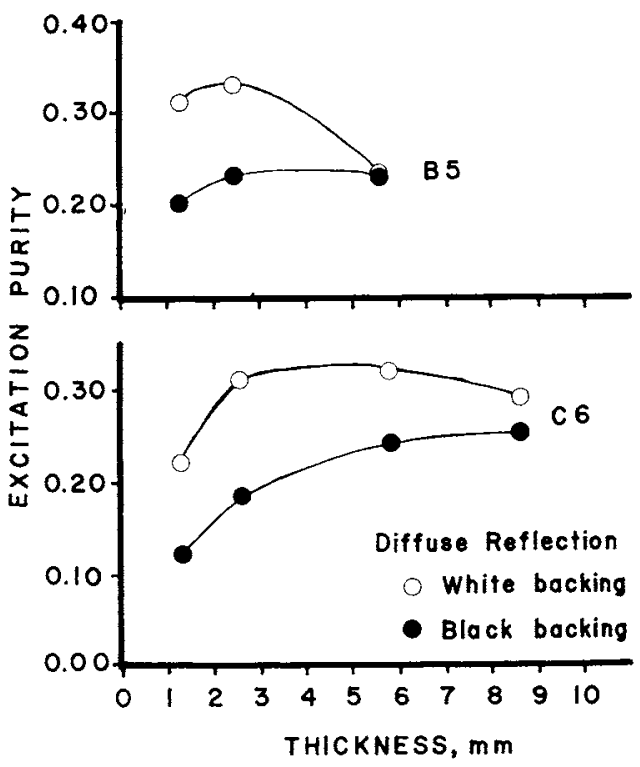

Fug 3.-Excitation purity versus thickness for white and black backing (diffuse reflection) for resins B5 and C6.

The effect of background color (condition b versus d) and thickness on the spectrophotometric parameters, luminous reflectance, dominant wavelength and excitation purity, was studied by analysis of variance. Computed values of $F$ for the main effects are listed in Table 1 for each resin as the ratio, $F_{Y}: F_{P}: F_{W}$. The interaction between the main effects was also significant, except where indicated otherwise. Of the three spectrophotometric parameters, luminous reflectance was affected the most by background color and thickness. Except for resin B10, background color caused a 
TABLE 1

Values of the F-Statistic Expressed as a Ratio $F_{Y}: F_{P}: F_{W}$

\begin{tabular}{lcc}
\hline & Background Color & Thickness \\
\hline B 5 & $4260: 745: 9.89^{*}$ & $3812: 127: 20.2$ \\
B 10 & $1610: 559: 16.4$ & $1880: 35.1: 11.3$ \\
C 6 & $21,400: 1740: 13.3^{*}$ & $13,700: 603: 21.4$ \\
C 11 & $62,500: 1420: 2.20^{*}, \dagger$ & $8480: 844: 8.07$ \\
\hline
\end{tabular}

* A significant interaction between background color and thickness was not observed.

$\dagger$ F-value was not significant at the $95 \%$ level of confidence.

larger effect than thickness. A plot of the contrast ratio $\left(Y_{b} / Y_{d}\right)$ versus thickness is shown in Figure 2 for each resin.

Excitation purity also was affected by background color and thickness as indicated in Table 1 but to a lesser extent than luminous reflectance. For each resin, background color caused a larger effect than thickness. Values of excitation purity are plotted as a function of thickness for conditions $b$ (black backing) and $\mathrm{d}$ (white backing) for resins $\mathrm{B} 5$ and $\mathrm{C} 6$ in Figure 3 and for resins B10 and C11 in Figure 4. The Scheffe interval for comparisons among values of excitation purity for resins $B 5$ and C11 was 0.006 for background color and 0.009 for thickness. For resins B10 and C6 the Scheffe interval was 0.005 for background color and 0.010 for thickness. For all resins the excitation purity was higher for measurements with the white standard (condition d) than with the black standard (condition b). The effect of thickness on excitation purity was similar for resins $\mathrm{C} 6$ and $\mathrm{C} 11$ but was more complex for resins $\mathrm{B} 5$ and $\mathrm{B} 10$.

Of the three spectrophotometric parameters, dominant wavelength was affected the least by background color and thickness as indicated in Table 1. For all resins except B10, thickness caused a larger effect than background color. Values of dominant wavelength are plotted as a function of thickness for conditions $\mathrm{b}$ and $\mathrm{d}$ for resins $\mathrm{B} 5$ and $\mathrm{C} 6$ in Figure 5 and for resins $\mathrm{B} 10$ and $\mathrm{C} 11$ in Figure 6. The Scheffe interval for comparisons among values of dominant wavelength for resins B5 and C11 was $2.7 \mathrm{~nm}$ for background color and $4.2 \mathrm{~nm}$ for thickness. For resins B10 and C6 the Scheffe interval was $2.3 \mathrm{~nm}$ for background color and $4.9 \mathrm{~nm}$ for thickness. For all resins except C11, the dominant wavelength was significantly lower for measurements with the white standard than with the black standard for the thinner samples ( $T=1.30$ and $2.50 \mathrm{~mm}$ ); for thicker samples there were no significant differences. Except for resin B10 under condition $\mathrm{b}$, dominant wavelength increased significantly with increased thickness, but not more than about 3 percent.

\section{Discussion}

The color associated with the spectrophotometric parameters, luminous reflectance, excitation purity and dominant wavelength, is described in a visual system such as Munsell* by the value, chroma, and hue relative to CIE standard illuminant C. ${ }^{6}$ Chromaticity coordi-

- Munsell Color, Balitmore, Md 21218.

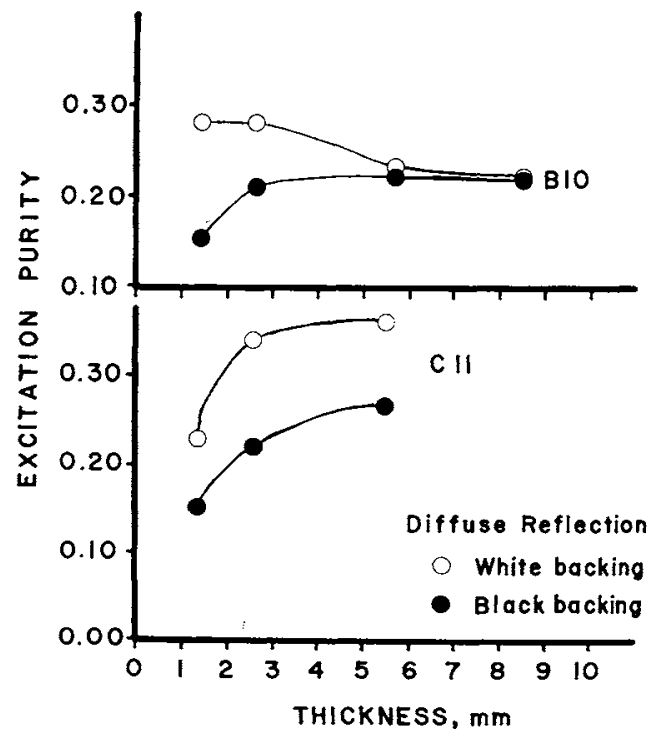

FIG 4.-Excitation purity versus thickness for white and black backing (diffuse reflection) for resins $\mathrm{B} 10$ and $\mathrm{C} 11$. 
TABLE 2

Comparison of Differences in Spectrophotometric Parameters

Caused by Changes in Munsell. Parameters

\begin{tabular}{|c|c|c|c|}
\hline \multirow[b]{2}{*}{ Change in Munsell Parameter } & \multicolumn{3}{|c|}{ Change in Spectrophotometric Parameter* } \\
\hline & Luminous Reflectance & Excitation Purity & Dominant-Wavelength \\
\hline Value: $2.5 \mathrm{R} 5.5 / 6$ to $2.5 \mathrm{R} 6 / 6$ & $\begin{array}{l}24.58 \text { to } 30.05 \\
(5.47) \dagger\end{array}$ & No change & No change \\
\hline Chroma: $2.5 \mathrm{R} 6 / 6$ to $2.5 \mathrm{R} 6 / 8$ & No change & $\begin{array}{l}0.19 \text { to } 0.25 \\
(0.06)\end{array}$ & $\begin{array}{l}618 \text { to } 620 \\
\text { (2) }\end{array}$ \\
\hline Hue: $2.5 \mathrm{R} 6 / 6$ to $5.0 \mathrm{R} 6 / 6$ & No change & $\begin{array}{l}0.19 \text { to } 0.24 \\
(0.05)\end{array}$ & $\begin{array}{l}618 \text { to } 605 \\
\quad(13)\end{array}$ \\
\hline $\begin{array}{l}\text { Scheffe interval computed in } \\
\text { this study }\end{array}$ & 0.03 & 0.01 & 5 \\
\hline
\end{tabular}

* Based on conversion ${ }^{2}$ of Munsell data relative to CIE standard illuminant $C$.

$\dagger$ Difference between two values.

nates and luminous reflectance corresponding to a Munsell color can be obtained from conversion tables, ${ }^{2}$ so that its dominant wavelength and excitation purity can be determined by the aforementioned graphical technique with the use of a CIE chromaticity diagram (1931). By use of this conversion technique, perceptible differences in color as denoted by changes in Munsell value, chroma and hue can be related to corresponding differences in luminous reflectance, excitation purity, and dominant wavelength. This comparison of differences is made in Table 2 for a Munsell color

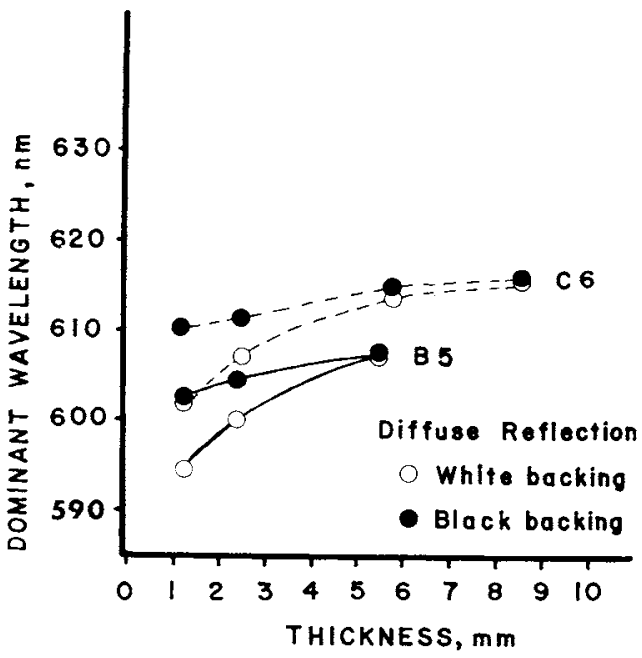

FIG 5.--Dominant wavelength versus thickness for white and black backing (diffuse reflection) for resins B5 and C6.
(2.5R 6/6) typical of the resins studied. ${ }^{1}$ Also listed are the largest of the Scheffe intervals determined in this study. The spectrophotometer is clearly more sensitive to changes in luminous reflectance than the visual system, but not so dramatically sensitive to changes in excitation purity or dominant wavelength. The ability of a trained observer to interpolate between neighboring color tabs to 0.1 units of value, 0.4 units of chroma, and 0.5 units of hue suggest that changes of about 1.1 units in luminous reflectance, 0.012 units in excitation purity and $2.2 \mathrm{~nm}$ in dominant wavelength as measured by a spectrophotometer also could be detected visually.

Clinically the effects of specular reflection on the appearance of a denture would be to

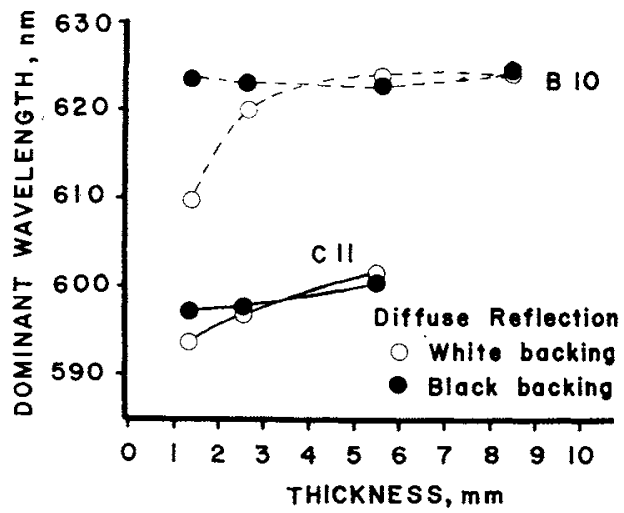

FIG 6.--Dominant wavelength versus thickness for white and black backing (diffuse reflection) for resins $\mathrm{B} 10$ and $\mathrm{C} 11$. 
lighten the color and to reduce the saturation of color independent of the thickness of the denture. The ability of a denture to mask the color of the supporting tissues depends on the opacity of the resin and the thickness of the denture. When the contrast ratio is less than one, the lightness or darkness of the supporting tissues will influence the appearance of the denture. Tissues lighter in value will result in a denture that is lighter in appearance, more saturated in color, and less purple in hue. The effect of the hue and chroma of the supporting tissues on the color of a denture also would be important, but has not yet been investigated. Also, the effect of changes in surface texture on the appearance of the resins has not been evaluated.

\section{Conclusions}

The effect of specular reflection, background color, and specimen thickness on the color of four commercial denture resins was studied by reflection spectrophotometry. Specular reflection increased the luminous reflectance, and decreased the excitation purity, but had no effect on the dominant wavelength of the resins when compared to data obtained by diffuse reflection only. Higher values of $\mathrm{lu}$ - minous reflection and excitation purity were obtained with a white than with a black background, whereas values of dominant wavelength were lowered slightly. The effect of background color was less dramatic for the more opaque resins and thicker sections.

\section{References}

1. Powers, J.M., and Koran, Andrew: Color of Denture Resins, J Dent Res 56:754-761, 1977.

2. Wyszecki, G., and Stiles, W.S.: Color Science, New York, Wiley \& Sons, Inc., 1967, $628 \mathrm{pp}$.

3. Opacity of Paper, D589-65 (1970), In ASTM Standards 1975, part 20. Philadelphia, American Society for Testing Materials, 1975 , pp. 86-88.

4. University of Michigan, Statistical Research Laboratory, BMD8V-Analysis of Variance. Ann Arbor, Statistical Research Laboratory, 1968, $4 \mathrm{pp}$.

5. Guenther, W.C.: Analysis of Variance, Englewood Cliffs, N.J.: Prentice-Hall, Inc., 1964, 141 pp.

6. Specifying Color by the Munsell System, D1535-68 (1974). In ASTM Standards 1975, part 20. Philadelphia, American Society for Testing Materials, 1975, pp. 383-404. 